\title{
A Case of Infectious Purpura Fulminans: An Unusual Organism and Method of Diagnosis
}

\author{
Pei Chia Eng ${ }^{a}$, Catherine Bryant ${ }^{a, b}$, Stephen H.D. Jackson ${ }^{a, b}$ \\ a Department of General Medicine, Kings College Hospital, London, United Kingdom \\ ${ }^{\mathrm{b}}$ Department of Clinical Gerontology, Kings College Hospital, London, United Kingdom
}

\begin{abstract}
:
Infectious purpura fulminans is a rapidly progressive skin necrosis that has a mortality rate of $30 \% \%^{1,2}$. Here, we describe a case of infectious purpura fulminans caused by Capnocytophaga, diagnosed by a blood film.
\end{abstract}

Keywords: Capnocytophaga, purpura fulminans, bacillus, sepsis

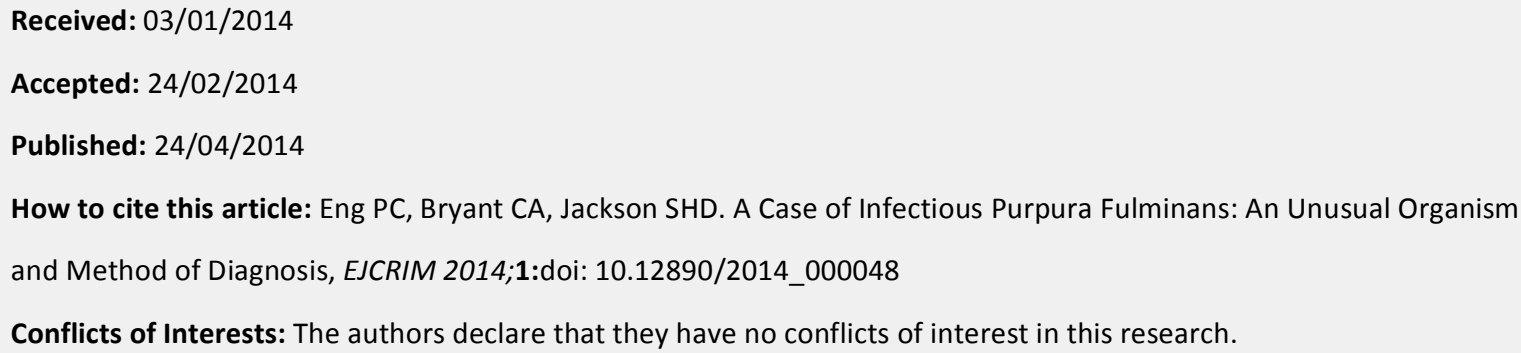

\section{Introduction}

Infectious purpura fulminans is a rapidly progressive skin necrosis that has a mortality rate of $30 \%^{1,2}$. Here, we describe a case of infectious purpura fulminans caused by Capnocytophaga, diagnosed by a blood film.

\section{Case report}

A previously healthy 66-year-old man presented to the emergency department with a history of less than 24 hours of feeling unwell, fever, non-productive cough and vomiting. He had not been exposed to anyone sick in the recent past and had no past medical history.

On admission, he was pyrexic at $38.3^{\circ} \mathrm{C}$, tachycardic at 125 beats per minute and tachypnoeic at 33 breaths per minute. His blood pressure was $88 / 61 \mathrm{mmHg}$. On auscultation, there were minimal 
crepitations at both lung bases. All other physical examinations were normal. Biochemistry results demonstrated a raised white cell count with left shift, acute kidney injury, deranged liver function and disseminated intravascular coagulation (Table 1).

\begin{tabular}{|c|c|c|}
\hline & Laboratory value & Reference range \\
\hline \multicolumn{3}{|l|}{ Biochemistry } \\
\hline C-reactive protein & $284 \mathrm{mg} / \mathrm{l}$ & $<5 \mathrm{mg} / \mathrm{l}$ \\
\hline Sodium & $143 \mathrm{mmol} / \mathrm{l}$ & $135-145 \mathrm{mmol} / \mathrm{l}$ \\
\hline Potassium & $3.4 \mathrm{mmol} / \mathrm{l}$ & $3.5-5.0 \mathrm{mmol} / \mathrm{l}$ \\
\hline Creatinine & $240 \mu \mathrm{mol} / \mathrm{l}$ & $45-120 \mu \mathrm{mol} / \mathrm{l}$ \\
\hline eGFR corrected for ethnic group & 21 & $>90 \mathrm{ml} / \mathrm{min} / 1.73 \mathrm{~m}^{2}$ \\
\hline Urea & $8.1 \mathrm{mmol} / \mathrm{l}$ & $3.3-6.7 \mathrm{mmol} / \mathrm{l}$ \\
\hline Phosphate & $1.76 \mathrm{mmol} / \mathrm{l}$ & $0.80-1.40 \mathrm{mmol} / \mathrm{l}$ \\
\hline Corrected calcium & $2.09 \mathrm{mmol} / \mathrm{l}$ & $2.15-2.60 \mathrm{mmol} / \mathrm{l}$ \\
\hline Total protein & $66 \mathrm{~g} / \mathrm{l}$ & $60-80 \mathrm{~g} / \mathrm{l}$ \\
\hline Albumin & $36 \mathrm{~g} / \mathrm{l}$ & $35-50 \mathrm{~g} / \mathrm{l}$ \\
\hline Globulin & $30 \mathrm{~g} / \mathrm{l}$ & $25-35 \mathrm{~g} / \mathrm{l}$ \\
\hline Bilirubin (total) & $26 \mu \mathrm{mol} / \mathrm{l}$ & $3-20 \mu \mathrm{mol} / \mathrm{l}$ \\
\hline Alkaline phosphatase & $159 \mathrm{IU} / \mathrm{I}$ & $30-130 \mathrm{IU} / \mathrm{I}$ \\
\hline Aspartate transaminase & $515 \mathrm{IU} / \mathrm{I}$ & $10-50 \mathrm{IU} / \mathrm{I}$ \\
\hline Gamma-glutamyl transferase & $251 \mathrm{IU} / \mathrm{I}$ & $1-55 \mathrm{IU} / \mathrm{I}$ \\
\hline \multicolumn{3}{|l|}{ Haematology } \\
\hline White blood cells & 16 & $4-11 \times 10^{9}$ cells $/ \mathrm{l}$ \\
\hline Red blood cells & 4.08 & $4.5-5.8 \times 10^{12}$ cells $/ \mathrm{l}$ \\
\hline Haemoglobin & 10.8 & $13-16.5 \mathrm{~g} / \mathrm{dl}$ \\
\hline Mean corpuscular volume & 88.2 & $77-95 \mathrm{fl}$ \\
\hline Platelets & 24 & $150-450 \times 10^{9}$ cells $/ \mathrm{l}$ \\
\hline Neutrophils & 10.46 & $2.2-6.3 \times 10^{9}$ cells $/ 1$ \\
\hline Lymphocytes & 1.08 & $1.3-4 \times 10^{9}$ cells $/ \mathrm{l}$ \\
\hline Monocytes & 0.55 & $0.2-1.0 \times 10^{9}$ cells $/ \mathrm{l}$ \\
\hline Basophils & 0.06 & $0-0.1 \times 10^{9}$ cells $/ \mathrm{l}$ \\
\hline Fibrinogen & 5.5 & $1.5-4 \mathrm{~g} / \mathrm{l}$ \\
\hline INR & 2 & $1.0-1.5$ \\
\hline
\end{tabular}

Table 1: Initial blood test results of the patient during admission 
Chest radiograph showed possible right basal consolidation. A computed tomography of his chest, abdomen and pelvis showed features of an infarcted spleen, with no evidence of intra-abdominal collections. A diagnosis of sepsis of unknown origin was made and intravenous Tazocin (piperacillin and tazobactam) was commenced at $4.5 \mathrm{~g}$ twice a day. Five litres of intravenous saline, $1 \mathrm{I}$ of colloid and $15 \mathrm{ml} / \mathrm{kg}$ of fresh frozen plasma were administered. Continuous haemodialysis was instigated in the Medical Critical Care Unit (MCCU). Despite all therapeutic efforts, the patient became progressively hypotensive and was intubated, mechanically ventilated and treated with milrinone and noradrenaline. Within the first few hours in the MCCU, he developed cutaneous blistering, initially on the left arm, later progressing rapidly, forming areas of widespread ecchymosis involving the thorax, abdomen, digits, lower limbs and nose tip (Figs. 1 and 2).

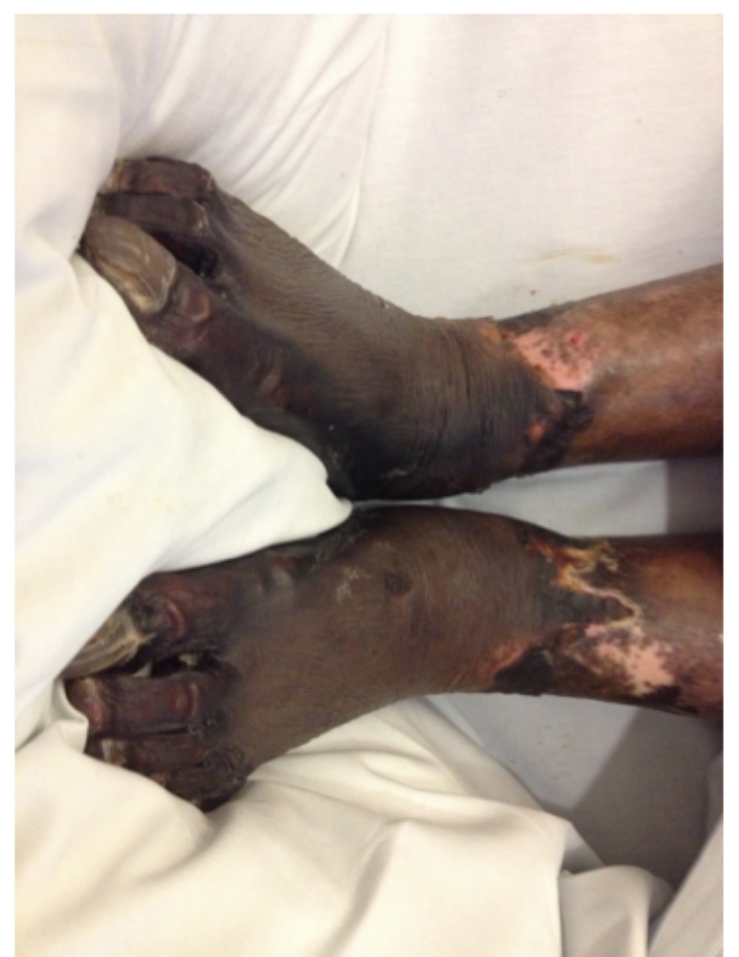

Figure 1: Purpura fulminans leading to peripheral gangrene in the feet.

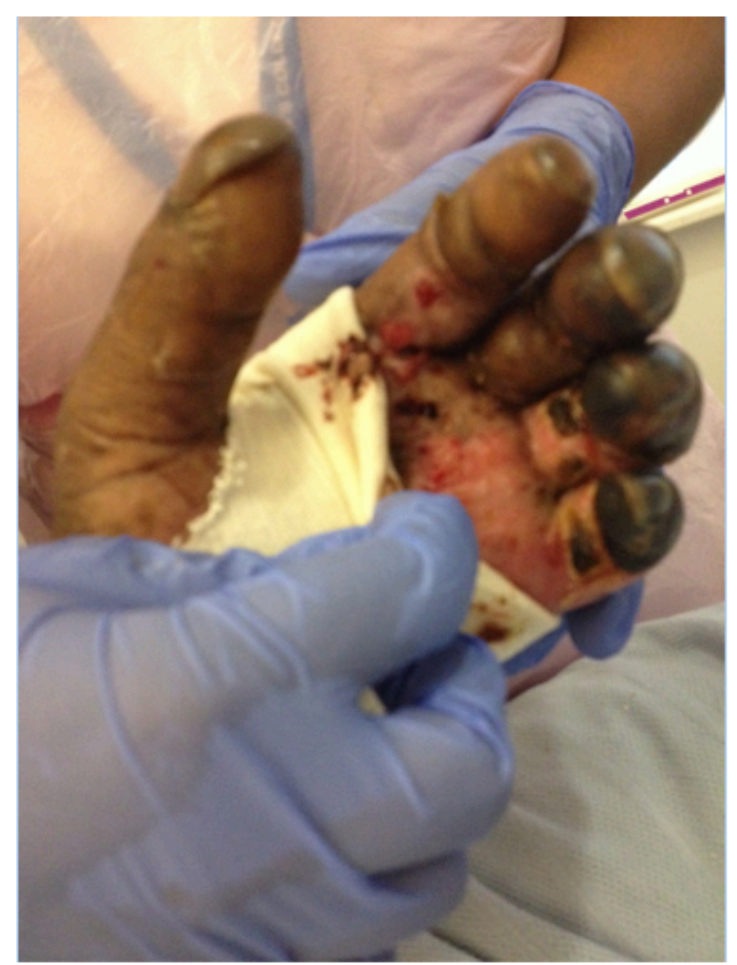

Figure 2: Purpura fulminans leading to peripheral gangrene in the hands.

Sepsis due to meningococcal disease or staphylococcal/streptococcal infection was suspected and antibiotic treatment was escalated to intravenous clindamycin, ciprofloxacin, Tazocin and linezolid.

\section{Investigations}

The initial blood cultures showed no growth. These blood cultures were sent for prolonged incubation on chocolate agar and again no growth was detected. The urine culture and wound swab showed no growth. His retroviral test was negative. The combined nose and throat swab showed absence of influenza $A$, influenza $B$, respiratory syncytial virus, parainfluenza virus type 1,2 and 3 and adenovirus. Cytomegalovirus, Epstein-Barr virus and hepatitis screens were negative. Sputum culture showed no acid-fast bacilli. Urine pneumococcal antigen was negative. 
A second set of blood cultures grew Candida glabrata. The positive fungal culture suggested a possible occult infection although fundoscopy examination was normal and neither the transthoracic echocardiogram nor transoesophageal echocardiogram showed any vegetations.

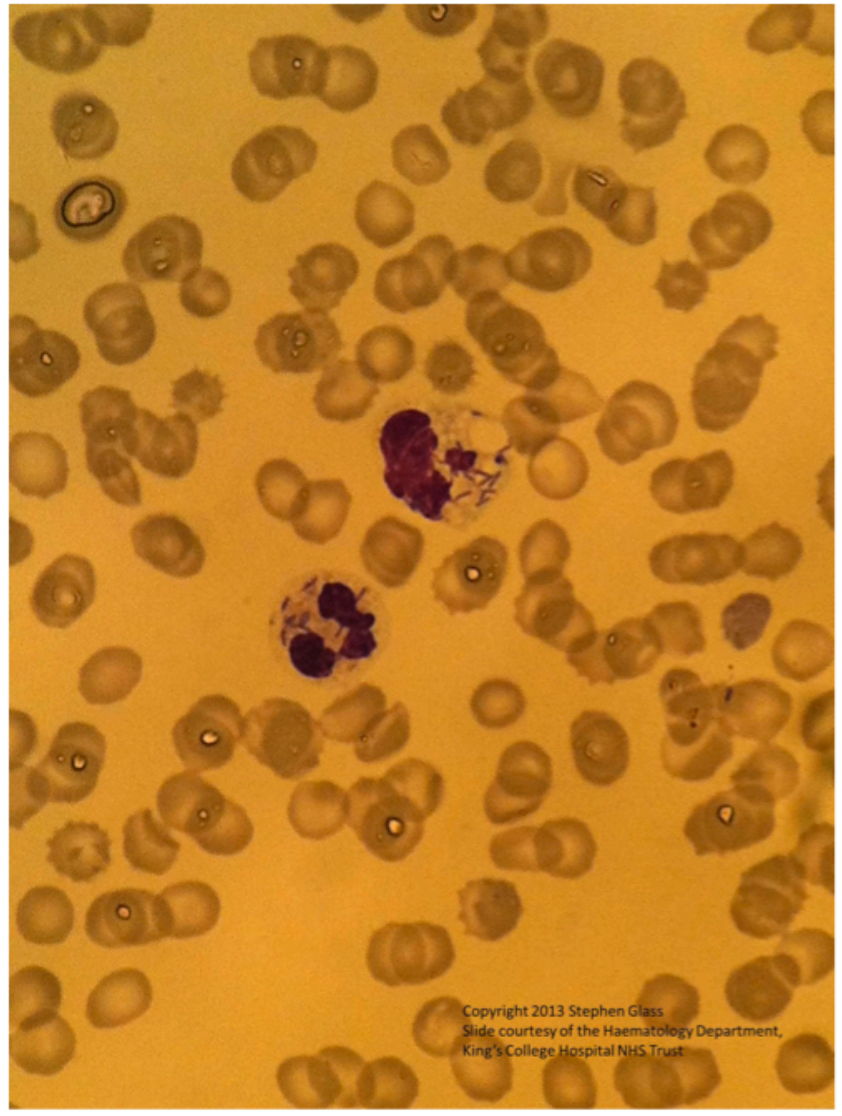

Figure 3: A peripheral blood smear showing intracellular bacilli in neutrophils

The central venous line, peripheral line and nasogastric line tips were negative for bacterial and fungal growth. Intravenous amphotericin B was added to the antibiotic regimen but it was agreed that the fungal growth was not the primary focus of infection.

The focus of infection remained unclear, until results of a peripheral blood smear (Fig. 3) showed rod-like inclusions consistent with an intracellular bacterium, raising a suspicion of Capnocytophaga canimorsus septicaemia. This was supported by the patient's history. A family dog had bitten the patient 48 hours prior to the onset of symptoms; the bite marks were superficial. The dog was up to date with vaccinations. Antibiotic therapy was changed to meropenam, given reports of beta-lactam-resistant strains of the Capnocytophaga species. The areas of ecchymoses on the nose, lower limbs and fingertips became necrotic, requiring surgical debridement.

\section{Outcome}

The patient had 14 days of intravenous meropenam. He eventually had bilateral below-knee amputations and became wheelchair bound, requiring ongoing rehabilitation.

\section{Discussion}

C. canimorsus is a gram-negative, non-spore-forming bacillus found in the gingival flora of cats and dogs. It is transmitted to man by bites ( $54 \%$ of cases), scratches $(8.5 \%)$ or by mere exposure to animals $(27 \%)^{2,3}$. Human infection with this bacterium is rare. It tends to occur at greater frequency in those who are immunocompromised (5\%) and those with asplenia (33\%), alcoholism (24\%), chronic lung disease and cirrhosis ${ }^{4,5}$. Despite its low virulence, $50 \%$ of patients suffering from $C$. canimorsus septicaemia develop severe purpura fulminans. The mortality rate is $30 \%$ and prompt diagnosis is essential|-5. 
Patients with $C$. canimorsus infections present with nonspecific signs such as nausea, vomiting and shortness of breath and progress rapidly to septic shock. Few develop a maculopapular rash at the site of the animal bite ${ }^{4,5}$. Some patients develop haemorrhagic adrenal insufficiency ${ }^{6}$. There are also rare instances of $C$. canimorsus endocarditis or meningitis ${ }^{7,8}$.

As $C$. canimorsus is a fastidious, slow-growing organism, isolation of this organism is difficult. Culturing of $C$. canimorsus involves using an enriched agar such as chocolate, $5 \%$ sheep blood, heart or brain-heart infusion agar with $5 \%$ rabbit blood at $37^{\circ} \mathrm{C}$. Colonies may not be visible for up to 7 days. Even with meticulous culture conditions, blood cultures are negative in $30 \%$ of cases $^{9,10}$. Some authors have suggested identification of $C$. canimorsus through polymerase chain reaction (PCR) and 16 s ribosomal RNA gene sequencing ${ }^{11}$, but such facilities are not readily available in all centres.

C. canimorsus infection can cause organ failure. The mechanisms involve widespread inflammatory response secondary to endotoxin production. The systemic influx of the local inflammatory mediators causes tissue toxicity, microvascular ischaemia and cell death ${ }^{12}$. Treatment involves early targeted antibiotic therapy and intensive organ support ${ }^{12,13}$. C. canimorsus infection responds well to penicillin and $\beta$-lactam- $\beta$-lactamase inhibitor combinations. Other active agents include clindamycin, linezolid, tetracycline, carbapenems and chloramphenicol ${ }^{14}$. Due to the increasing frequency of $\beta$-lactamase-resistant strains, meropenam was chosen ${ }^{14,15}$. Though monoclonal anti-endotoxin antibodies have been used in gram-negative sepsis, there are still insufficient clinical studies to prove its benefit ${ }^{16,17}$.

\section{Learning Points}

- C. canimorsus-induced septicaemia, though rare, should be considered in any patients presenting with sepsis.

- A history on animal exposure, previous foreign travel and recent contacts is vital.

- Waiting for blood culture could delay treatment. Alternative methods of diagnosis should be considered.

\section{References}

1. Smith OP, White B. Infectious purpura fulminans: diagnosis and treatment, $\mathrm{Br} J$ Haematol 1999;104:202-207.

2. Christiansee $C B$, Berg RM, Plovsing RR, Moller K. Two cases of infectious purpura fulminans and septic shock caused by Capnocytophaga canimorsus transmitted from dogs, Scan J Infect Dis 2012;44:635-639.

3. Brenner DJ, Hollis DG, Fanning GR, Weaver RE. Capnocytophaga canimorsus sp. Nov (formerly CDC group DF-2), a cause of septicaemia following dog bite and C. cynodegmi sp Nov., cause of localized wound infection following dog bite, J Clin Microbiol 1989;27:231- 
235.

4. Kullberg BJ, Westendorp RG, Van't Wout JW, Meinders AE. Purpura fulminans and symmetrical peripheral gangrene caused by Capnocytophaga canimorsus (formerly DF-2) septicaemia: a complication of dog bite, Medicine (Baltimore) 1991;70:287-292.

5. Dire DJ, Hogan DE, Riggs MW. A prospective evaluation of risk factors of infection from dog wounds, Acad Emerg Med 1994;258-266

6. Mirza I, Wolk J, Toth L, Rostenburg P, Kranwinkel R, Sieber SC. Waterhouse-Friderichsen syndrome secondary to Capnocytophaga canimorsus septicemia and demonstration of bacteria by peripheral blood smear, Arch Pathol Lab Med 2000;124:859-863

7. Risum M, Ellekvist P. Capnocytophaga canimorsus meningitis diagnosed by means of a $16 \mathrm{~S}$ rRNA analysis, Ugeskr Laeger 2012:174:280-281.

8. Hayani O, Higginson LA, Toye B, Burwash IG. Man's best friend? Infective endocarditis due to Capnocytophaga canimorsus, Can J Cardiol 2009;25:130-132.

9. Ciantar M, Spratt DA, Newman HN, Wilson M. Assessment of five culture media for growth and isolation of Capnocytophaga spp, Clin Microbiol Infect 2001;July:158-160.

10. Janda MJ, Graves MH, Lindquist D, Probert WS. Diagnosing Capnocytophaga canimorsus infections, Emerg Infect Dis 2006;12:340-342.

11. De Melo Olicerira MG, Abels S, Zbinden R, Bloemberg GV, Zbinden A. Accurate identification of fastidious Gram-negative rods: integration of both conventional phenotypic methods and 16S rRNA gene analysis, BMC Microbiol 2013;13:162.

12. Bone RC. Gram-negative sepsis: a dilemma of modern medicine, Clin Microbiol Rev 1993;6:57-68.

13. Munford RS. Severe sepsis and septic shock : role of gram-negative bacteremia, Annu Rev Pathol 2006;467-496.

14. Jolivet-Gougeon A, Sixou J-L, Tamanai-Shacoori Z, Bonnaure-Mallet M. Antimicrobial treatment of Capnocytophaga infections, Int J Antimicrob Agents 2007;29:367-373.

15. Lloret A, Egberink H, Addie D et al. Capnocytophaga canimorsus: $A B C D$ guidelines on prevention and management, J Feline Med Surg 2013;15:588-590.

16. Wedel NI, Gorelick KJ, Saria EA, Weidler DJ, Blaschke TF. Pharmacokinetics and safety of antiendotoxin antibody E5 in normal subjects, Crit Care Med 1990;18:S212.

17. Zhou F, Peng Z, Murugan R, Kellum JA. Blood purification and mortality in sepsis: a meta-analysis of randomized trials, Crit Care Med 2013;41:2209-2220. 